\title{
DOS MODELOS DE CRISIS SUICIDA. UNA PERSPECTIVA CLIINICA
}

\section{TWO MODELS OF SUICIDAL CRISIS. A CLINICAL PERSPECTIVE}

\author{
Juan García-Haro \\ FEA Psicología Clínica
}

Centro de Salud Mental de Adultos. Pola de Siero. Asturias

Servicio de Salud del Principado de Asturias. Asturias. España

\section{Marta González González}

Psicóloga Interna Residente

Servicio de Salud del Principado de Asturias. Asturias. España

Henar García-Pascual

Enfermera Especialista en Salud Mental

Servicio de Salud del Principado de Asturias. Asturias. España

Cómo referenciar este artículo/How to reference this article:

García-Haro, J., González González, M. y García-Pascual, H. (2018). Dos modelos de crisis suicida. Una perspectiva clínica. Revista de Psicoterapia, 29(111), 167-185.

\section{Resumen}

La problemática suicida es sin duda una de las más dificiles para los profesionales de salud mental. En la ayuda a personas con riesgo suicida se camina muchas veces a tientas, desprovistos de un esquema conceptual que sirva para explicar-comprender dicha conducta. Sin un entendimiento de la vulnerabilidad de la persona y de los procesos de la crisis suicida, dificilmente se podrá dar una ayuda que sea efectiva, por mucho que la investigación apunte a diversos parámetros biomédicos supuestamente explicativos de la conducta suicida. En este artículo se presentan dos modelos psicológicos para la comprensión clínica de la crisis suicida: el modelo psicoanalítico y el existencial. Se concluye que ambos modelos, solos o en combinación, pueden ser de gran utilidad en la evaluación y planificación de la ayuda terapéutica que reciben las personas que consultan por motivos suicidas.

Palabras clave: existencial, psicoanálisis, psicopatología, suicidio, intento de suicidio

\begin{abstract}
The suicidal problem is undoubtedly one of the most difficult for mental health professionals. In helping people at risk of suicide, they often walk blindly without a conceptual framework that serves to explainunderstand such behavior. Without an understanding of the persons vulnerability and the processes of suicidal crisis, it will be difficult to give effective help, no matter how much the research points to various supposedly explanatory of the suicidal crisis biomedical parameters. In this article, we present two psychological models for the clinical understanding of the suicidal crisis: the psychoanalytic model and the existential one. It is concluded that both models, alone or in combination, can be very useful in the evaluation and planning of the therapeutic help received by people who consult for suicidal reasons.
\end{abstract}

Keywords: existential, psychoanalysis, psychopathology, suicide, attempted suicide.

Fecha de recepción: 18-07-2018. Fecha de aceptación v1: 05-10-2018. Fecha de aceptación v2: 17-10-2018.

Correspondencia sobre este artículo:

E-mail: juanmanuel.garciah@sespa.es

Dirección postal: C/ Alonso Ojeda, 9, 6ํㅡㄹ. 33208 Gijón, Asturias. España

(C) 2018 Revista de Psicoterapia 
El amor tiene la virtud, no de desnudar, uno frente a otro, a los dos amantes, sino a cada uno de los dos frente a sí mismo (El oficio de vivir, C. Pavese, 1976, p. 158).

Todos saben muy bien, en alguno de los rincones de su alma, que el suicidio es, en efecto, una salida, pero muy vergonzante e ilegal, que en el fondo es más noble y más bello dejarse vencer y sucumbir por la vida

misma que por la propia mano

(El lobo estepario, H. Hesse, 1987, p. 53).

\section{Introducción}

"Mi vida no tiene sentido. No veo futuro. No tengo ganas de nada. Sólo pienso en morir. A todas horas. En cada momento. Creo que sería lo mejor. Así al menos me quitaría de encima todos estos problemas".

"Me falta una razón para querer vivir, no es que me quiera suicidar, es que no sé para qué vivir, no tengo ninguna satisfacción, mi vida es una mierda, emocionalmente no tengo ninguna relación, no tengo trabajo, necesito una motivación".

"Ya me da todo igual. Todo me agota, todo me cansa. Estoy harta de tirar para adelante. Ya no me importa nada. No veo futuro. Me siento una carga para los demás. A veces pienso que si me muriera todos estarían mejor".

Estas declaraciones pertenecen a tres consultantes recientemente atendidas en un Centro de Salud Mental de Asturias. Todas ellas apuntan a la problemática del suicidio si bien lo hacen con diferentes matices y desde diferentes perspectivas, pues el suicidio no es un fenómeno unitario sino heterogéneo.

La problemática suicida es sin duda una de las más difíciles que enfrenta el profesional sanitario. En el desarrollo y mantenimiento de las conductas suicidas se imbrican numerosos factores: culturales, sociales, psicológicos, clínicos y biológicos. Esto dificulta una adecuada evaluación y, por tanto, la aplicación de una ayuda efectiva.

Cuando se trata de entender la experiencia y conducta suicida, hay básicamente dos modelos: un modelo biomédico que tiene su foco de interés en el análisis de parámetros neuronales, bioquímicos o genéticos asociados al suicidio, y un modelo contextual-fenomenológico (García-Haro, García-Pascual y González González, en prensa) que sitúa la experiencia y conducta suicidas en el afronte dramático del sujeto con los embates de su vida y donde la sintomatología presentada funcionaría más como un indicador o dimensión de gravedad del sufrimiento biográfico y fracaso de las soluciones.

Para que la prevención y la ayuda terapéutica, más allá de la detección y diagnóstico, sea lo más efectiva posible, se precisa conocer los procesos implicados en la crisis suicida. En este sentido, desde la investigación psicológica se han formulado diferentes modelos explicativos denominados "multidimensionales" 
que pretenden arrojar luz al proceso suicida. Los modelos que cuentan con más apoyo empírico son los de diatesis-estrés (van Herringen, 2012). Habría una interacción entre factores de vulnerabilidad (factores distales del suicidio) y factores de estrés (factores proximales). Si los primeros son muy fuertes, un suceso vital negativo pequeño podría precipitar la conducta suicida y lo contrario: si el suceso negativo es muy fuerte, aún con poca vulnerabilidad se puede precipitar la conducta suicida. Con todo, son modelos formulados desde la abstracción teóricocientífica que apenas tienen aplicaciones prácticas o pistas de aterrizaje en la clínica-asistencial.

En la monografía de Rendueles dedicada al análisis de suicidios consumados, se consigna que el comentario más habitual entre los familiares es "nadie lo podía esperar, ni explicar" (Rendueles, 2018, p. 137). Con esto, se estaría apuntando a que en todo suicidio siempre hay un núcleo íntimo refractario a la investigación científica y que la pretensión de acceder al mismo, ya sea desde las causas biológicas o desde las motivaciones psicológicas, son arrogancias "psi" con escasa realidad (Rendueles, 2018, p. 187). Si bien admitimos que en muchas ocasiones es difícil poder llegar a entender el proceso implicado en el acto suicida, pensamos que no por ello hay que dejar de investigar y comprender esta compleja conducta humana. Más aún cuando su frecuencia se ha disparado en los últimos años.

El objetivo de este artículo es presentar dos modelos de crisis suicida: el modelo psicoanalítico y el existencial. Se eligen por su utilidad a la hora de entender-explicar la experiencia y conducta suicidas en el contexto clínico. Los dos enfoques tienen como paisaje de fondo la depresión vital o melancólica, si bien no se limitan a entender el suicidio desde la depresión, pues la misma depresión debería ser explicada contextualmente, toda vez que no es causa del suicidio sino más bien efecto de una psico-biografía determinada. Ambos modelos cuentan con el apoyo de numerosos relatos de personas que acuden a los servicios públicos de salud mental. También cuentan con el apoyo numerosas narraciones literarias. Se hablaría de "evidencia-basada-en-la-práctica", si bien faltaría aún la "evidencia" experimental. Aunque cada enfoque pone el énfasis en unas variables u otras, se pueden complementar. Se cierra el trabajo con algunas de las principales conclusiones.

\section{Modelo Psicoanalítico}

Se plantean dos enfoques: el clásico o freudiano y el enfoque relacional.

\section{Teoría freudiana}

Por lo que se refiere al suicidio, la teoría freudiana sigue una secuencia. Parte de la experiencia de pérdida de un objeto o relación valiosa, ya sea por muerte, frustración, decepción amorosa, etc. Continúa con el deseo de recuperar dicho objeto o relación perdida. Luego, ante la verificación de la imposibilidad real de recuperar dicho objeto (tristeza), tiene lugar una identificación del yo con el objeto perdido (identificación narcisista). Si la ambivalencia amor/odio inherente a toda 
relación afectiva es intensa, aparecerán elementos de culpa, los cuales estarán a la base de diferentes conductas autodestructivas (autodesprecio, autorreproches, autolesiones, etc.), que acabarán por introducir al sujeto en la depresión melancólica (Freud, 1972). En el límite de estas conductas autodestructivas estaría la conducta suicida como una forma de dirigir la agresión hacia el objeto interno antes idealizado.

La conducta suicida puede responder a múltiples motivaciones. Así, también puede verse como una forma de unión con el objeto perdido (Garma, 1973). Esta puede ser la motivación del suicidio de Melibea. Aquí, habría una identificación del yo con la persona querida y hasta con el modo de morir de dicha persona. Tras la muerte accidentada de su amado Calisto al descender por la escala que lo había llevado a su habitación, Melibea decide suicidarse tirándose de una torre.

Melibea: "Cortaron las hadas sus hilos, cortáronle sin confesión su vida, cortaron mi esperanza, cortaron mi gloria, cortaron mi compañia. Pues iqué crueldad sería, padre mío, muriendo él despeñado, que viviese yo penada! Su muerte convida a la mía. Convídame y fuerza que sea presto, sin dilación, muéstrame que ha de ser despeñada, por seguille en todo. No digan por mí: "a muertos y a idos..." Y así, contentarle he en la muerte, pues no tuve tiempo en la vida" (De Rojas, 1991, p. 334).

Una variante del esquema anterior (el suicido como autoagresión) es cuando el suicidio procede de una frustración o abuso continuado del contexto relacional inmediato, continúa con la imposibilidad de descargar la agresión al exterior, entonces, dado ese bloqueo, al no ser liberada la agresión, esta vuelve contra el yo del sujeto. Esto es lo que da sentido a la siguiente cita de Freud: "ninguna persona experimenta impulsos al suicidio que no hayan sido primero impulsos homicidas hacia otras personas y vueltos luego contra el yo" (Freud, 1972). Siendo así, cuando el contexto relacional inmediato deja de ser frustrador o abusador, desaparece la incubación de la agresión y con ello cesan también los deseos suicidas.

También, puede verse la conducta suicida como una manera de satisfacer una venganza, ya sea esta activa (consigue dañar al otro con su propia muerte) o pasiva (consigue evitar ser objeto del daño que viene del otro) (Garma, 1973).

La tesis de la agresión primaria al exterior, secundariamente vuelta contra el yo, puede verse en la literatura. Como dijo Augusto Pérez, personaje principal de la novela de Unamuno Niebla, en un paradójico encuentro con el autor de la misma novela: "Los más de los suicidios son homicidas frustrados; se matan a sí mismos por falta de valor para matar a otros...” (Unamuno, 1982, p. 213). El escritor italiano Cesare Pavese dejó escrito unos días antes de suicidarse en su diario íntimo lo siguiente: "Los suicidas son homicidas tímidos. Masoquismo en lugar de sadismo" (Pavese, 1976, p. 314).

A favor de esta interpretación psicoanalítica se señala lo siguiente: analizando en consulta episodios de autointoxicaciones en adultos, y de autolesiones en adolescentes, se verifica que coinciden con conflictos familiares o de pareja que 
activan intensos deseos destructivos hacia figuras importantes de relación pero cuya descarga queda inhibida en última instancia. La persona dice no sentir ninguna emoción de enfado o rabia. Cabe interpretar, no sin cierto riesgo de trapecista, que la autolesión dirige la destructividad hacia el yo, al tiempo que alivia culpas inconscientes. Por otro lado, el consumo de alcohol o de fármacos protegería anestesiando dicho estado de agresividad y culpa. En ambos casos se cortocircuita la actuación heteroagresiva.

Aunque parezca contradictorio, lo cierto es que para suicidarse hay que tener cierta distancia respecto a la situación-límite. Cuando el sujeto está lidiando con un conflicto del exterior pone en marcha mecanismos de supervivencia que funcionan en el aquí-y-ahora inmediato. Durante la Segunda Guerra Mundial la tasa de suicidio disminuyó. La existencia de actitudes agresivas externalizadas preserva, al menos temporalmente, del cambio de dirección hacia sí mismo. Esto da sentido a las palabras del novelista norteamericano Ernest Hemingway cuando decía que se pasaba la vida matando animales en la caza y la pesca para no matarse a sí mismo (Martin, 2006). Desde una perspectiva psicoanalítica se propone que al descargar la agresión al exterior, la disposición suicida se atenúa. Sólo cuando la lucha con el exterior ha caído, cuando hay una pérdida del "objeto" sobre el que descargar la agresividad, al quedar bloqueada su liberación, la retrae, la culpa y la vergüenza se ceba sobre uno mismo, se abre la puerta del suicidio.

A veces esas figuras abusadoras o persecutorias que han dañado profundamente al sujeto han sido figuras importantes de su infancia y como consecuencia de sus actos han dejado en el niño o niña un déficit y un núcleo de agresividad que va a perturbar sus relaciones afectivas. En la infancia este núcleo se puede manifestar en forma de fantasías asesinas y narraciones catárticas en diarios y cuentos. A medida que pasan los años, esta agresividad muchas veces sigue ahí, a modo de "mochila", acompañando al sujeto a lo largo de su viaje vital, dispuesta siempre a encontrar una víctima de descarga. Cuando esa víctima es el self, se comete suicido.

Visto así, el suicidio, lejos de ser un acto de autoaniquilación, encerraría siempre una dimensión relacional; vendría a convertirse en el "homicidio" de un objeto interno que antes era externo. Esto explicaría los intentos más/menos explícitos de culpabilizar a figuras del medio que muchas veces rodea al suicidio.

Mucho se ha hablado de la influencia de la culpa en el suicidio. Sobre todo de la influencia de las culpas depresivas. Una frase común de los suicidas es la siguiente: "Lo siento mucho; he hecho daño a todo el mundo; estarian mejor sin mi" (Grinberg, 1983). Aquí conviene señalar que, desde el punto de vista de la investigación, se verifica que los efectos patogénicos de la culpa se producirían o serían mayores cuando esta emoción aparece fusionada a la vergüenza (deterioro de la autoimagen) (Tangney y Dearing, 2002). Sería entonces cuando la culpa llevaría a la rumia obsesiva, a la evitación social, a la autocondena y a la autocrítica destructiva del self. Se sugiere a partir de esto, que muchas de las interpretaciones de Freud sobre las implicaciones de la culpa en los trastornos psicológicos serían 
en propiedad interpretaciones sobre la culpa-fusionada-a-vergüenza. Véase la descripción que hace Freud de la melancolía en Duelo y melancolía:

"Este nos describe su yo como indigno de toda estimación, incapaz de rendimiento valioso alguno y moralmente condenable. Se dirige amargos reproches, se insulta y se espera la repulsa y el castigo. Se humilla ante todos los demás y compadece a los suyos por hallarse ligado a una persona tan despreciable. No abriga idea ninguna de que de que haya tenido efecto en él una modificación, sino que extiende su crítica al pasado y afirma no haber sido nunca mejor" (Freud, 1972, p. 2093).

Se deja aquí la hipótesis de si la depresión melancólica no es acaso una autodepreciación como consecuencia de su fracaso en conseguir los objetivos del yo o la imagen de un self ideal.

Hasta aquí el modelo freudiano.

Los elementos anteriores (pérdida del objeto, idealización, deseo de unión con la persona fallecida, inhibición de la agresividad, culpa, etc.), se entrecruzan y quedan entreverados en el siguiente relato clínico:

Clara (los nombres son ficticios) es una mujer de 47 años, vecina de un pueblo de Asturias, casada, madre de un hijo de 25 años. De figura redonda y cara afable. Tiene un hermano mayor que también está casado.

Acude a consulta derivada por el servicio de Psiquiatría del Hospital Central Universitario de Asturias que recomienda ayuda psicoterapéutica tras ingresar por un intento de suicidio. Lleva varios años diagnosticada de depresión melancólica y ha realizado varios intentos de suicidio con múltiples ingresos. Vive con su marido Mario y su hijo en casa de los padres de Mario. Se fueron a vivir a casa de los suegros tras la muerte de la madre de Mario a los pocos años de casados. Según cuenta, esto fue un gran cambio para ella. Refiere haberlo llevado mal al principio aunque luego dice que lo aceptó. En los últimos años Clara se ha ocupado sumisamente de los cuidados del suegro. Comenta que en ocasiones éste la trata mal pero que ella lo calla y pone buena cara.

En el análisis de su historia personal comenta que tuvo una infancia dificil con una madre que no daba afecto, ni reconocimiento, y que tenía una clara preferencia estimativa por el hijo varón. De sus recuerdos infantiles a la única persona que salva es a su padre. Sin embargo, este falleció de un cáncer cuando Clara tenía 8 años. Poco después su madre inicia una nueva relación con Jorge, un vecino del pueblo, con quién acaba casándose. Clara comenta que Jorge le dio el afecto que le faltaba de su madre. Refiriéndose a Jorge dice: "fue como un padre, se volcó en mí y yo en él”. Así fue que consiguió tirar adelante y hacer su vida como mujer adulta sin que la falta de reconocimiento y el rencor que sentía hacia su madre le impidieran evolucionar. Dice que no es rencorosa, que tiene capacidad para perdonar y olvidar los daños recibidos. Clara se casa joven y tiene un hijo. Todo va aparentemente bien hasta que fallece Jorge de forma inesperada hace 8 años. Entonces aparecen los primeros deseos y tentativas de suicidio de Clara hasta 
entonces desconocidos. Lo explica diciendo: "quería irme con él”. En su discurso idealiza la figura de Jorge. Esto hace que Mario se sienta minusvalorado. Piensa que las cosas no fueron así como las cuenta Clara. Según Mario, Jorge nunca se ocupó de ella. Clara responde: "era muy bueno conmigo aunque a veces llegaba borracho".

Luego descubrimos que no todo iba bien en la pareja. Cuando fallece Jorge, Clara y Mario habian tenido una crisis de pareja que motivó el regreso de Clara al domicilio de su madre. Tras la primera tentativa suicida volvieron a unirse como familia.

Por otro lado, la madre de Clara, que lleva años viuda, sigue manteniendo un contacto preferencial por el hijo varón. Esto enfada a Clara, pero lo guarda en silencio. Cuando su madre la visita, cosa que hace muy a menudo, y muchas veces para criticar, Clara la recibe amistosa y servicialmente. En las muchas ocasiones en que ha estado hospitalizada, en ninguna ocasión su madre ha ido a verla.

Mientras tanto, el hijo ha pasado a ser el cuidador principal de la madre y la relación de Clara con su marido pasa a un segundo plano.

En el análisis de la secuencia de hechos que rodea a la última tentativa se pone de manifiesto lo siguiente: En los últimos años Mario tiene la rutina de salir con frecuencia de la casa sin decir el destino ni el para qué. Clara cree que sale a beber y a jugar a las máquinas. Esto enfada a Clara pero lo guarda y adopta una postura de resignación: "siempre fue asi". A veces Mario llega bebido. La última vez llegó de madrugada. Clara lo recibió con indiferencia, pero esa noche con toda tranquilidad, se toma una caja entera de pastillas con intención suicida. Avisan al 112 y la vuelven a ingresar. Tras el alta dice que es consciente de su enfermedad y que no concibe su vida sin su marido y sin su hijo: "Yo creo que no lo voy a hacer porque me necesitan". Dice con tono triste no querer molestar a nadie, desea que los demás hagan su vida, que no se preocupen de ella, se hace autorreproches de que hace sufrir a todos, de que todos estarían mejor sin ella.

\section{Enfoque relacional}

Desde la psicología del self, se piensa que una de las motivaciones principales del suicidio viene del fracaso a la hora de lograr la identidad o imagen que impone el ideal del yo. Este fracaso puede precipitar una vergüenza insufrible (asociada a una crisis narcisista) y una desesperación que sería la que precede al acto suicida. Esto ocurriría sobre todo cuando la distancia entre el self actual y el self ideal no se elabora o se compensa con otros módulos del self o ámbitos de relación que puedan suturar la herida narcisista y ayudar a recuperar la autoestima perdida. Un prototipo en este sentido de compensación podría ser el caso del escritor japonés Yukio Mishima con el culto a la estética corporal como compensación de una autoimagen deteriorada (Mishima, 2010).

Cuando se invierte un gran esfuerzo vital en conseguir la imagen idealizada, pero esta no se logra, la persona puede quedar invadida por el odio hacia sí misma. 
Este odio puede expresarse a través de numerosos de mecanismos autodestructivos, desde los autorreproches, hasta la aniquilación total de sí mismo. Este podría ser el caso de Hemingway. Se dice que la imagen idealizada del novelista cristalizó en torno a la búsqueda de la maestría, de un triunfo vengativo que le elevara por encima de los demás (Yalom y Yalom, 1971). También podría encajar aquí el caso de Mishima: dedicó sus últimos años a una frenética obsesión; conseguir un cuerpo imponente y una musculatura de "sol y acero". Trataba así de lograr el ideal del samurái o del guerrero trágico. Según declaración propia, a medida que su físico ganaba en musculatura y fuerza, fue desarrollando una tendencia a la aceptación del dolor y un interés cada vez mayor por el sufrimiento físico y la muerte (Mishima, 2010). Esta tendencia, junto con su proyecto fracasado de influir políticamente en los jóvenes japoneses, le llevaría hasta la autodestrucción final en forma de seppuku.

Como decíamos, ante el fracaso del logro del self ideal, se cae en lo que Morrison (2008) llama "depresión de vergüenza". Esta modalidad de depresión puede estar a la base de diferentes conductas autodestructivas, incluyendo como límite el suicidio. Vergüenza y auto-desprecio humillante (junto a proyección de la grandiosidad en el otro idealizado aunque perdido) hacia la persona que uno es, estarían relacionadas con la caída del narcisismo y con el suicidio. El suicidio sería aquí la forma agresiva que tiene el sujeto de acabar con una vergüenza intolerable que inunda al self o que anticipa.

Morrison (2008) habla de la "dialéctica del narcisismo" para describir la tensión siempre presente entre dos estados del self: el polo expansivo (asociado a lo grandioso) y el polo contraído (asociado a la depreciación). Cada polo puede retroceder o bien hacerse más dominante. Si en el polo expansivo los elementos de autodesprecio están silenciados, en el polo contraído son los aspectos grandiosos los que permanecen en la sombra. Ambos siempre están, pero unos y otros se ocultan el protagonismo.

Kinston ha señalado que la propensión a la vergüenza y la vulnerabilidad narcisista, aunque relacionadas entre sí (Morrison, 1997, 2008), son dos nociones diferentes. Si bien todos los sujetos propensos a sentir vergüenza, son narcisísticamente vulnerables, lo contrario no es cierto. La razón es que muchas personas narcisísticamente vulnerables se encierran en una invulnerabilidad defensiva (Kinston, 1983) o en una grandiosidad defensiva (Morrison, 2008). Esto ocurriría especialmente en las llamadas personalidades narcisistas de "piel fina", más que en las de "piel dura". Esto es, en personas hipersensibles a la evaluación y a la crítica, que se sienten heridas con facilidad y, por tanto, más vulnerables a reaccionar con rabia, vergüenza o humillación. Pueden mostrar incluso un estado de ánimo triste fusionado con el enfado intenso y que conviene no confundir con la depresión clínica, por mucho que exista riesgo de suicidio. Este narcisismo de "piel fina" sería más propio de las personalidades del núcleo confusional (fóbica, confusa, explosivo-bloqueada) que de las del núcleo esquizoide (esquizoide, 
agresiva, narcisista) (Caparrós, 1992a, 1992b).

La agresividad y la venganza rabiosa hacia los demás podría funcionar aquí como una forma de evitar la toma de conciencia de una autoimagen deteriorada o como una forma de ocultarse a sí mismo la distancia entre el self actual y el self ideal (Lansky, 2007; Morrison, 2008). También podría funcionar como un intento de recuperar la autoestima perdida (Kinston, 1983). Y a nuestro juicio, como una manera de no suicidarse. Se trataría en cualquier caso de una vergüenza-rabiosa o una rabia-fusionada-a-vergüenza.

Las heridas narcisistas pueden generar estados de profunda desesperación que pueden estar a la base distal o proximal de la vulnerabilidad suicida. Aquí, se destacarían sobre todo las heridas debidas a fracasos amorosos. En estos casos, la víctima puede quedar profundamente afectada llegando incluso a elegir renunciar a seguir viviendo sin el objeto de amor. Esto pasaría si se elige la fusión-amorosacon-un otro-idealizado como único proyecto de ser o como la única razón para vivir. El caso de la joven escultora Marga Gil Roësset lo ilustra perfectamente: tras verificar la imposibilidad de su amor por el poeta Juan Ramón Jiménez decidió dispararse un tiro en la cabeza en 1932. Véase en este sentido el "Diario de Marga" (Jiménez, 2015). Aunque no se llegue a tal extremo, lo cierto es que cuando se analizan estos fracasos amorosos, se advierte enseguida que no se trata tanto del objeto perdido, cuanto de la herida narcisista que implica el haber sido rechazado como sujeto. En este caso el self se autodeprecia porque ha sido depreciado. Este parece haber sido el caso del escritor italiano Cesare Pavese: rechazado primero por Tina ("la mujer de la voz ronca"), al final de su vida por la actriz Constance Dowling (Lester, 2006; Pavese, 1976) y por él mismo a través del suicidio. Desde esta perspectiva, el suicidio sería la culminación de la serie autodestructiva.

Otro ilustre suicida (aunque aquí hay dudas de si realmente lo fue) que debió enfrentar importantes heridas narcisistas (y no pocas y graves heridas físicas), fue Ernest Hemingway: mientras se recuperaba de una lesión en la Primera Guerra Mundial se enamoró profundamente, probablemente por primera vez, de Agnes von Kurowsky, una de las enfermeras que le atendía. Después de la guerra, Hemingway regresó a los Estados Unidos dispuesto a casarse con ella, pero finalmente nunca se vieron. Agnes había elegido a otra pareja (Martin, 2006; Yalom y Yalom, 1971).

Con todo, quizás lo importante no sea, con serlo, el hecho de haber sufrido pérdidas o abusos en la infancia, si no el vínculo de apego en los primeros años. Así tendríamos una tabla de cuatro variables categóricas: haber sufrido o no pérdidas $o$ abusos en la infancia y haber tenido un apego seguro o inseguro. Un apego inseguro (modelo interno negativo, o en otras palabras: vulnerabilidad narcisistasensibilidad a la vergüenza y por tanto confusión de identidad y tendencia al autodesprecio) asociado a factores de pérdida suicida y abusos en la infancia sería lo más propicio para un desarrollo suicida. Esto es, para iniciar un proceso de incubación de la idea suicida que acompaña al sujeto el resto de su vida.

Se podría decir por tanto que antes del acto de quitarse la vida hay todo un 
recorrido que se inicia en la infancia-adolescencia y atraviesa sin abandonarla la vida entera de la persona. Así se puede leer el diario íntimo de Cesare Pavese (Pavese, 1976), la biografía de Hemingway (Martin, 2006, Yalom y Yalom, 1991) y la novela autobiográfica "Confesiones de una máscara" de Yukio Mishima (1985, Ushijima, 1987), entre otros.

Como ejemplo de apego inseguro tendríamos el caso de Hemingway. Se dice que de niño su padre era autoritario y maltratador mientras que su madre le vestía de niña y lo descalificaba, lo cual podría haber estado a la base de un intenso rechazo hacia ambos del que derivaban intensas fantasías agresivas contra su padre. Cuando su padre se suicidó de un tiro en la cabeza en 1928. Hemingway no dudó en culpabilizar a su madre y desde entonces la odió abiertamente (Martin, 2006) y por extensión, añadimos nosotros, a todas las mujeres, y quizás también a sí mismo.

Para terminar:

Desde la óptica psicoanalítica y situados ahora en el punto de vista de la evaluación y la ayuda terapéutica, convendría reparar en lo siguiente:

1. La inhibición de la agresividad así como la vergüenza y la autodepreciación del self serían variables fundamentales a considerar en la evaluación del riesgo suicida.

2. En la atención a personas con riesgo suicida, sobre todo si se trata de personas narcisísticamente vulnerables, se precisaría establecer una relación terapéutica segura, empática y confirmatoria que haga que la persona se sienta acogida y reconocida.

3. Ayudar a vaciar la "mochila" de su carga "explosiva-agresiva", moderar la autodepreciación (autoaceptación) y elaborar la vergüenza, pueden ser tareas u objetivos terapéuticos a tener en cuenta.

\section{Modelo Existencial}

El modelo existencial procede de la pérdida o conciencia de pérdida y fracaso del proyecto y la imposibilidad para rehabilitar el mismo, y que luego, desde ese vacío y desesperanza (depresión vital), se comete la conducta suicida como una forma de solución existencial (Castilla del Pino, 2013).

Para saber qué es el suicidio quizás conviene empezar por saber qué es la vida humana. Sirva para este propósito la analítica de la razón vital de Ortega (1966, 1974).

La vida humana -dice Ortega- la de cada persona, la mía, la tuya, la de él, la de ella, es lo que hacemos y nos pasa. Su sustancia consiste en estar-ahí-haciendoalgo para llenar ese vacío-de-ser con el que nos encontramos de pronto en la existencia. En efecto, cada persona no tiene otro remedio que estar-ahí-haciendoalgo para sostenerse en la existencia, enfrentando o achicando la angustia incesante que viene de las preocupaciones existenciales básicas. Desde la Psicoterapia Existencial (Yalom, 1984, 2000, 2008), estas preocupaciones serían: 1) la muerte, 2) la libertad, 3) el aislamiento-soledad y 4) la falta de un sentido vital o proyecto 
de vida.

Este estar-ahí-haciendo-algo consiste por de pronto en la tarea y responsabilidad (intransferible) de construir un proyecto de vida, una identidad, ser un "quién", que permita amortiguar a modo de defensa la inseguridad y la amenaza inherente a nuestra vulnerabilidad existencial y finitud personal. Más aún en tiempos de "modernidad líquida" (Bauman, 2017). La vida humana es, pues, anticipación de futuro, es ese estar de continuo decidiendo (libertad) lo que vamos a hacer (la agenda) y la-persona-que-queremos-ser (la identidad). En efecto, estar-decidiendola-persona-que-queremos-ser, es una tarea que sirve para enfrentar la inseguridad de estar-ahí sumergidos en una vida que no nos es dada hecha y acabada, sino vacía, indeterminada, por-hacer. Eso sí, se trataría de una tarea, brega o viaje sin garantía ninguna de éxito; o mejor, donde el riesgo de mal-lograr el proyecto, de llegar-aser, de naufragar, siempre está al acecho, lo cual, bien mirado es bastante obvio, pues un proyecto lo es en tanto que puede no llevarse a cabo, y de ahí la angustia existencial. Esta angustia funcionaría no tanto como un síntoma mental a apagar (ruido psicopatológico) según entiende el modelo biomédico de salud mental, sino como un indicador del afronte dramático yo-mundo. Esto es, como expresión de las dificultades en la tarea de estar-decidiendo-la-vida, de estar-llegando-a-ser, y, por tanto, como un elemento biográfico-existencial a descifrar y asumir.

A modo de excursus: ¿Se suicidan los animales?

Desde la analítica de Ortega, sólo el ser humano se encuentra existiendo en una vida vacía e indeterminada, por hacer. Sólo el ser humano tiene conciencia y obligación de tener que construir su proyecto de vida. Al animal le es dado un repertorio más o menos invariable de conductas con las que vive. El animal vive, no "hace" su vida. Según lo anterior: ¿qué es el suicidio? Desde la analítica orteguiana cabría afirmar que es el acto de acabar con la angustia-sufrimiento que inunda o impide continuar con la vida biográfica hasta entonces valiosa. Visto así, sería bastante lógico pensar que el suicidio es un acto exclusivamente humano. Sería una opción del campo antropológico. Esta es la tesis del filósofo Simon Critchley (2016) entre otros. Los suicidios colectivos, las epidemias de suicidios, los suicidios por honor y venganza, etc., así lo atestiguan. Siendo el suicidio una conducta voluntaria dirigida contra la propia vida en busca de su autodestrucción, de no-ser, de ser-nada, de querer librarse del sufrimiento quitándose la vida, sería raro encontrar casos de animales que ejecuten la conducta suicida. Salvo en fábulas antropomórficas, claro está. Quizás la etología desmienta esta tesis. Con todo, se aluden a ciertos casos de escorpiones, delfines, etc., que cuando están en un contexto de amenaza de muerte inminente, ejecutan supuestamente una conducta suicida (véase el escorpión que se clava su propio aguijón al estar rodeado de fuego). Obligados como estamos, en el caso de los animales, a hacer análisis sólo-desdefuera, diríamos que el fenómeno de los suicidios animales caería del lado de mecanismos estímulo-respuesta sin conciencia. Que cometan suicidio buscando voluntariamente la muerte y sabiendo que ese será el resultado presupone la 
autoconciencia de la muerte, lo cual es difícil saber en los animales. La tesis de que los animales no se suicidan es también la posición que defienden autores como Durkheim en su libro clásico sobre el suicidio (2004), Primo Levi (2005) o Jean Améry (2005).

Desde la óptica existencial, la raíz de toda conducta suicida estaría en la ruptura del yo con su proyecto o la conciencia de pérdida total. "Mi vida es un fracaso" dicen muchos suicidas. Cuando esta conexión se rompe surge la angustia y la lucha por engancharse a la vida. Habría un periodo de lucha o de "desesperación", entendida como búsqueda agónica de una salida a la situación presente. Esfuerzo natatorio ante la posibilidad de ser tragado por las olas. Cuanto esta lucha desfallece, a modo de agotamiento según las fases del síndrome general de adaptación al estrés del Selye, se cae en la "des-esperanza", y desde ese vacío o derrota existencial (depresión vital o melancolía), se activa la idea del suicidio (que ya estaba ahí de alguna manera) como salida o escapatoria a un yo-mundo que se vive insoportable. Visto así, no debe confundirse "desesperación" con "desesperanza" (Laín Entralgo, 1978). Tampoco con "cansancio de la vida" (Laín Entralgo, 1975). En la desesperación se combate todavía. Hay una brizna de esperanza. En la desesperanza no sólo "no hay" (o uno siente que no hay) proyectos o perspectivas de futuro, sino que la persona "cree" estar segura o cierta de que nunca los tendrá, que nada en adelante va a cambiar el sentido de las cosas (Rojas, 1978). La desesperanza significa haber perdido toda posibilidad, no esperar nada, no tener proyecto de futuro (Castilla del Pino, 2013). Los proyectos hacen posible la vida como tarea, como empeño dirigido al futuro. Vale decir que quien no tiene proyectos es que ya la vida no le ofrece nada capaz de sacarlo de su letargo y lanzarlo hacia adelante, por tanto, está como en la antesala del dejar-de-ser: abocado a la muerte (Rojas, 1978). En un estudio sobre el suicidio, Rojas (1978) diferenciaba entre desesperanza y desesperación. Se encontró que en los suicidios frustrados el porcentaje de desesperanza era del $46,9 \%$. Mientras que el porcentaje de desesperación era del 17,3\%. Si sumamos sus porcentajes en el suicidio frustrado tenemos $64,2 \%$. Se apunta a que ante la imposibilidad de proyectar la existencia, se acaba uno suicidando. Así, pues, la desesperanza sería una caída del proyecto total de existencia, si bien nada quita que puedan existir ciertas metas parciales, puntuales, subsidiarias (hacer un viaje, aprobar un examen, hacer un curso, etc.). Es la misma distinción que establece la Terapia de Aceptación y Compromiso (Hayes, Strosahl y Wilson, 2015), entre valores (viajes que duran toda la vida) y metas (acciones que se pueden tachar de una lista). En la depresión melancólica, la des-motivación sería un síntoma de la ruptura del sujeto con su proyecto. Siendo así, el suicidio sería una solución a una pérdida total del proyecto. Esta pérdida de contacto con el proyecto junto con la sensación de pérdida de esperanza en el futuro sería lo que activa en el depresivo el suicidio. Sería contraproducente aquí el comentario banal de querer señalarle a la persona en crisis que las cosas no son así, que el proyecto elegido sigue siendo valioso a pesar de todo, que otros proyectos serán posibles. 
Cuando, por el motivo que sea, se cae en la cuenta (fundada o infundada) de haber equivocado el proyecto, y de que ya no hay tiempo (biográfico) para subsanarlo (edad avanzada), se cae en la depresión o en el suicidio. El suicidio, en esta perspectiva, sería, como decimos, un intento de huir del error existencial o de evitar la realidad (fracaso) del proyecto vital (Castilla del Pino, 2013). Es duro admitir que uno estaba equivocado, que ha vivido buena parte de la vida arrastrado por una concepción equivocada que nunca había cuestionado. Se pone aquí a prueba la capacidad de elaborar las heridas narcisistas.

La falta de un horizonte proyectivo en "mi vida" personal, de poder-ser, sería pues una antesala del suicidio. Esto ocurriría sobre todo si además hay soledad o desamparo. Esto es, cuando al sentimiento de desesperanza le acompaña una percepción de nulo apoyo social. El alcohol aquí puede levantar el freno conductual y facilitar el acto suicida.

Desde luego, como señala Rendueles (2018), la idea de un decisor racional que realiza cálculos objetivos entre beneficios y desventajas está muy desacreditada en la ciencia experimental. Ahora bien, fuera del laboratorio de la ciencia, en la vida ordinaria de la persona, no se ve claro cómo se podría saber a ciencia cierta si uno es o no un decisor racional. ¿En qué nos basamos para juzgar si nuestra vida ha sido valiosa o no, o si lo volverá a ser en el futuro? ¿Acaso hay un criterio externo y objetivo al que recurrir para evaluar este asunto? La racionalidad objetiva es más un mito sobrehumano sólo al alcance de los dioses. Los juicios cognitivos muchas veces están tamizados por los afectos. Habría que hablar más bien de un decisor "pático", en lugar de racional, aunque a veces resulte un decisor más bien patético. Utilizamos el término "pático" en el sentido estimativo de aceptación/rechazo, simpatía/antipatía, etc., que nos provocan los objetos de la circunstancia (Castilla del Pino, 2000). En efecto, es muchas veces el "cómo yo lo siento" la base de nuestras decisiones-acciones. De ahí el riesgo suicida aumentado cuando se cae en estados de depresión, pues la tristeza vital y la culpa matizan todas las percepciones biográficas y balances existenciales. Esto es lo que hace el escritor Cesare Pavese unos días antes de suicidarse; hacer balance de su persona y obra. Véase lo escrito los días 16 y 17 agosto de 1950 en su Diario íntimo "El oficio de vivir" (Pavese, 1976).

"Veo hoy claramente que desde los veintiocho años hasta vivi siempre bajo esta sombra, alguien diría un complejo. Y que lo diga: es algo mucho más simple" (Pavese, 1976, p. 314).

Véase también:

"Ya no tengo nada que desear en esta tierra, excepto aquella cosa excluida por quince años de fracasos. Este es el balance del año no terminado, que no terminaré" (Pavese, 1976, p. 315).

Esta parada en el camino a modo de "epojé", que permite valorar la propia existencia, es válida también para el joven y para el adulto, pues nadie está exento de realizar balances existenciales. Eso sí, a medida que avanza la edad hay más 
materia a examen sobre lo que ha sido "mi vida". También podría ocurrir lo contrario: que el balance vital sea posterior a la decisión de suicidarse y en este caso sería más su efecto. Primero se tomaría la decisión y luego, para evitar la disonancia cognitiva, se buscarían las razones biográficas o las culpas para inclinar la balanza hacia la muerte.

Como se dijo antes, cabría pensar en un desarrollo suicida incubado desde mucho tiempo antes, quizás desde la adolescencia o juventud, acaso a modo de elección originaria del Psicoanálisis Existencial sartreano (Sartre, 1996). Esto es, a modo de una decisión de ser que es la que funda y determina un destino. El diario íntimo de Pavese (1976) y la novela autobiográfica "Confesiones de una máscara" de Mishima (1985), admiten esta lectura.

¿Cómo se articulan entre sí la esperanza y el proyecto? La esperanza lanza la flecha de la vida hacia el futuro. Es el andamio o cimbra que sirve a construir el proyecto. Es el puente que une el presente con el futuro, actuando como un empuje que pide que el proyecto se concrete de algún modo. El proyecto -dice Laín Entralgo- es la forma propia y primaria de la espera humana (Laín Entralgo, 1978). No tener esperanza es tanto como no tener vida. El lenguaje popular lo dice claramente: "la esperanza es lo último que se pierde". Y "mientras haya vida, hay esperanza". La esperanza es la confianza más/menos firme o segura que tenemos en que se cumplirán las distintas posibilidades existenciales que proyectamos en el futuro. En cambio, sin esperanza (des-esperanza) no hay puente, ni andamio, ni proyecto, ni futuro, ni vida, ni posibilidad de ser. Sin proyectos no hay vida humana. La desesperanza sería un terreno fértil donde germinan las ideas y conductas de suicidio. Es lo que se llama "diselpidia" (de "elpis", esperanza); la incapacidad para proyectarse en el futuro, para vivir la vida con esperanza (Laín Entralgo, 1978). Este factor se podría indagar con la siguiente pregunta: ¿Hasta qué punto sientes que los problemas que te agobian se van a solucionar en el futuro? Se recordará a este propósito que Van Gogh dejó escritas estas palabras justo antes de suicidarse: " $E l$ futuro es cada vez más sombrio y no veo ninguna esperanza de felicidad" (Jaspers, 2003, p. 240).

Por tanto, en la comprensión existencial del suicidio depresivo habría cuatro momentos:

1. Caída del proyecto de vida.

2. Angustia y lucha por reconstruir el proyecto.

3. Vacío y desesperanza (depresión vital).

4. Deseos y acto de suicidio.

Cuando el sujeto logra andamiar un nuevo proyecto, la crisis suicida disminuye. Ayudar a llenar los aljibes y albercas del alma de sentido y esperanza sería pues una vía de ayuda para las personas en situación de riesgo o vulnerabilidad suicida. Transformar la desesperanza en esperanza. Deseo de más vida y no sólo prevención de la muerte.

Desde el punto de vista preventivo y terapéutico, la Terapia Existencial tendría 
aquí su utilidad. Se podrían situar tres perspectivas terapéuticas:

1. La Terapia del Desarrollo Moral (TDM) (Villegas, 2011, 2013 y 2015) y su énfasis en la libertad y la autonomía como eje de los diversos subsistemas de regulación moral. Según Villegas, la TDM aporta dos dimensiones básicas que estaban ausentes en la perspectiva existencial: la evolutiva y la estructural (Villegas, 2018). En este sentido, la autonomía significa una redefinición del proyecto existencial. "Lo contrario supone la formación de un vacío que clínicamente se conoce con el nombre de depresión y que frecuentemente lleva a hundirse en la posición prenómica o a considerar, incluso, la alternativa del suicidio" (Villegas, 2018, p. 5).

2. La Terapia de Aceptación y Compromiso (ACT) (Hayes, Strosahl y Wilson, 2015) en su idea de ayudar a las personas a desarrollar una vida plena y basada en valores. Se han señalado ciertas afinidades de ACT con la línea existencial (véase García-Haro, García-Pascual y González González, 2018). Se trataría aquí de visualizar un horizonte de sentido que se puede haber perdido como consecuencia del combate con los problemas de la vida, a menudo por abuso de estrategias de control y/o evitación de experiencias internas indeseadas. Para visualizar este horizonte de sentido se requiere identificar valores, experiencias, recuerdos o aspectos valiosos que hayan dado sentido a su vida, razones de vivir que tuvo (pasado), tiene (presente) o tendría (futuro) si todo fuera bien. Crear vidas que merezcan la pena ser vividas, vidas con sentido, sería desde esta óptica un antídoto frente al vacío y la crisis suicida. Hay estudios que apuntan a la utilidad de ACT en personas con conducta suicida (véase Ducasse et al., 2014; Ducasse et al., 2018).

3. La Logoterapia (Frankl, 1988, 1990, 1996, 2008, 2016) en su dimensión de búsqueda y realización de sentido y dirección hacia los valores. Se diferencia tres clases de valores: 1) valores creativos (capacidad de trabajar y crear obras o aportar nuevos conocimientos), 2) valores experienciales o vivenciales (entrega amorosa a una persona o causa, velar por la calidad de los vínculos) y 3) valores actitudinales. Estos últimos son para Frankl los más importantes. Se ponen a prueba cuando el sujeto tiene que enfrentar una circunstancia externa inesperada y que no está en sus manos poder cambiar. Ante este sufrimiento trágico hay que tomar postura; aceptar dando sentido o rechazar condenándose a una lucha sin fin. Plasmado en una fórmula sintética: desesperanza $=$ sufrimiento - sentido (Frankl, 1985). Una aplicación de la Logoterapia al suicidio puede verse en Rocamora (2017).

\section{A Modo de Conclusión}

Se han presentado dos modelos de crisis suicida: el modelo psicoanalítico y el existencial. El primero apunta a la agresividad inhibida y la crisis narcisista como variables fundamentales en la dinámica del suicidio. El segundo sitúa como elementos clave de comprensión-explicación del suicidio la caída del proyecto, el vacío existencial y la desesperanza. Podemos encontrar cierta relación entre el modelo freudiano y el modelo existencial. Esta relación se pondría de manifiesto si 
cambiamos la "pérdida de objeto" por el "fracaso del proyecto". Se concluye que ambos modelos solos o en combinación pueden ser de gran utilidad en la orientación y planificación de la ayuda a personas con vulnerabilidad suicida. Descargar la agresividad, moderar la autocrítica (autoaceptación), elaborar la vergüenza, construir un proyecto de futuro, conectarse con valores y transmitir esperanza pueden ser dianas terapéuticas ("targets") que bien pueden aliviar la crisis suicida y posponer la opción de matarse.

\section{Epílogo: de la vida y el suicidio}

Queremos terminar con unas reflexiones a partir de la literatura y la poesía. Empezamos con una cita del escritor norteamericano Paul Bowles.

"Como no sabemos cuando vamos a morir,

llegamos a creer que la vida es un pozo inagotable.

Sin embargo, todo sucede solo un cierto número de veces, y no demasiadas. ¿En cuántas ocasiones te vendrá a la memoria aquella tarde de tu infancia?

Una tarde que ha marcado el resto de tu existencia.

Una tarde tan importante que ni siquiera puedes concebir tu vida sin ella.

Quizás cuatro o cinco veces, quizás ni siquiera eso.

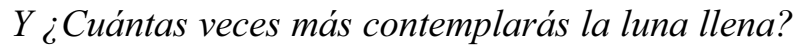

Quizás veinte. Y sin embargo, todo parece ilimitado".

(Paul Bowles, El cielo protector, B. Bertolucci, 1990).

Esta narración aparece en la escena final de la película "El cielo protector". Trata de la finitud y la temporalidad del ser, de la memoria y la omnipotencia. El tema de fondo es el modo ordinario en que vivimos la existencia y que se resumen con la cita de Freud que dice: "en lo inconsciente todos nosotros estamos convencidos de nuestra inmortalidad" (Freud, 1972, p. 2110). En efecto, vivimos de espaldas a la muerte como si nunca fuera a pasar en "mi vida". Uno procura estar ocupado en mil tareas, distraerse, ocultarse el vacío que nos habita, en definitiva; escamotear la muerte. Entonces llega la muerte de la persona querida y con su duelo nos despierta del sueño letárgico en que vivíamos, nos coloca ante la conciencia desnuda de nuestra mortalidad, más allá de "la gente muere". Así, no hay escape de la muerte. Un cuento sufí dice: "Hay quién vive como si nunca fuera a morir y muere como si nunca hubiera vivido". Se hace por tanto necesario vivir (hacer la vida) "contando con" la finitud y aceptación de la propia mortalidad.

"Sin miedo a morir,

la vida es un caballo desbocado que no sabe a dónde va".

En efecto, ser conscientes de la muerte, contar con la mortalidad, es la condición o a priori (y no sólo el límite) de mis proyectos futuros. Como decía Yalom $(1984,2008)$, si la muerte nos destruye, la idea de la muerte nos puede salvar.

La importancia de la muerte en la vida humana puede verse en la siguiente meditación sobre el suicidio: 
"Como uno sabe que puede poner fin a su vida cuando quiera

no tiene prisa en morir.

Vive como si fuera dueño de su destino.

Soporta sin miedo los agobios y frustraciones de la existencia,

pues tiene siempre a su disposición un arma para poner fin al sufrimiento.

Esta solución permite

paradójicamente

una actitud vitalista frente a la existencia;

Ayuda a vivir".

En efecto, la idea de suicidio puede tener cierto papel positivo al animar al náufrago a seguir nadando entre las olas de la vida. La opción del suicidio es la que permite a Harry Haller, protagonista del "El lobo estepario" (Hesse, 1987), a Ellen West, la famosa paciente de Binswanger (1977) y al escritor Cioran (1990), entre otros muchos, elegir seguir viviendo, a pesar de todo.

Cioran dijo: "Vivo únicamente porque puedo morir cuando quiera: sin la idea de suicidio, hace tiempo que me hubiera matado" (Cioran, 1990, p. 71).

Y la joven Ellen West: "Sin la esperanza del fin la vida sería intolerable. Lo único que me consuela un poco es la certeza de que tarde o temprano vendrá la muerte" (Binswanger, 1977, p. 295).

La escena final de la película "Frantz" (Ozon, 2016) condensa perfectamente la idea que queremos transmitir. La protagonista camina por una sala de museo. Se sienta frente al "El suicida" de Manet. Allí hay un joven que le pregunta:

"¿También le gusta este cuadro?”

Respuesta: "Sí, me da ganas de vivir".

\section{Referencias bibliográficas}

Altmaye, E. y Altmayer, N. (Productores) y Ozon, F. (Director). (2016). Frantz [Película]. París, Francia: Mandarin Cinema.

Améry, J. (2005). Levantar la mano sobre uno mismo. Discurso sobre la muerte voluntaria. Valencia, España: PreTextos.

Bauman, Z. (2017). Modernidad líquida. Madrid, España: Fondo de Cultura Económica.

Binswanger, L. (1977). El caso de Ellen West. Estudio antropológico-clínico. En R. May, E. Angel y H.F. Ellenberger(Eds.), Existencia. Nueva dimensión en psiquiatría y psicología (pp. 288-434). Madrid, España: Gredos.

Caparrós, N. (1992a). Psicopatología analítico-vincular. Tomo I. Madrid, España: Quipú.

Caparrós, N. (1992b). Psicopatología analítico-vincular. Tomo II. Madrid, España: Quipú.

Castilla del Pino, C. (2000). Teoría de los sentimientos. Barcelona, España: Tusquets.

Castilla del Pino, C. (2013). Un estudio sobre la depresión. En C. Castilla del Pino(Ed.), Obras Completas, Volumen I-II (1946-1966). Córdoba, España: Fundación Castilla del Pino-Universidad de Córdoba.

Cioran, E. M. (1990). Silogismos de la amargura. Barcelona, España: Tusquets.

Critchley, S. (2016). Apuntes sobre el suicidio. Barcelona, España: Alpha Decay.

De Rojas, F. (1991). La celestina. Madrid, España: Anaya. 
Ducasse, D., Jaussent, I., Arpon-Brand, V., Vienot, M., Laglaoui, C., Béziat. S., Calati, R., Carrière, I., Guillaume, S., Courtet, P. y Olié, E. (2018). Acceptance and Commitment Therapy for the Management of Suicidal Patients: A Randomized Controlled Trial. Psychotherapy and Psychosomatics, 87(4), 211-222. doi: $10.1159 / 000488715$

Ducasse, D., Rene, E., Beziat, S., Guillaume, S., Courtet, P. y Olie, E. (2014). Acceptance and commitment therapy for management of suicidal patients: a pilot study. Psychotherapy and Psychosomatics, 83(6), 374-376. doi: $10.1159 / 000365974$

Durkheim, E. (2004). El suicidio. Estudio de sociología. Madrid, España: Losada.

Frankl, V. E. (1985). Logos, paradoja y la búsqueda de significado. En M. J. Mahoney y A. Freeman (Eds.), Cognición y psicoterapia (pp. 283-299). Barcelona, España: Paidós.

Frankl, V. E. (1988). La voluntad de sentido. Barcelona, España: Herder.

Frankl, V. E. (1990). Logoterapia y análisis existencial. Barcelona, España: Herder.

Frankl, V. E. (1996). El hombre en busca de sentido. Barcelona, España: Herder.

Frankl, V. E. (2008). Ante el vacio existencial. Hacia una humanización de la psicoterapia. Barcelona, España: Herder.

Frankl, V. E. (2016).... A pesar de todo, sí a la vida. Tres conferencias y un esbozo autobiográfico. Barcelona, España: Plataforma.

Freud, S. (1972). Consideraciones de actualidad sobre la guerra y la muerte. En S. Freud, Obras Completas, Tomo $V I$ (pp. 2101-2117). Madrid, España: Biblioteca Nueva.

Freud, S. (1972). Duelo y melancolía. En S. Freud, Obras Completas, Tomo VI (pp. 2091-2100). Madrid, España: Biblioteca Nueva.

García-Haro, J., García-Pascual, H. y González González, M. (2018). Cuando los síntomas no dejan ver el sentido. Viaje existencial al centro de la psicoterapia. Revista de Psicoterapia, 29(109), 39-67. Recuperado de: http:/ /tienda.revistadepsicoterapia.com/catalog/product/view/id/1481/s/rp109-02/category/3/

García-Haro, J., García-Pascual, H. y González González, M. (en prensa). Enfoque contextual-fenomenológico sobre el suicidio. Revista de la Asociación Española de Psiquiatría.

Garma, A. (1973). Los suicidios. En M. Abadi, A. Garma, E. Garma, A. J. A. Gazzano, E. H. Rolla y N. Tampey, La fascinación de la muerte. Panorana, dinamismo y prevención del suicidio (pp. 63-104). Buenos Aires, Argentina: Paidós.

Grinberg, L. (1983). Culpa y depresión. Madrid, España: Alianza.

Hayes, S. C., Strosahl, K. y Wilson, K. G. (2015). Terapia de Aceptación y Compromiso. Proceso y práctica del cambio consciente (mindfulness). Bilbao, España: Desclée De Brouwer.

Hesse, H. (1987). El lobo estepario. Barcelona, España: Círculo de Lectores.

Jaspers, K. (2003). Genio artístico y locura. Strindberg y Van Gogh. Barcelona, España: Acantilado.

Jiménez, J. R. (2015). Marga. Sevilla, España: Fundación José Manuel Lara.

Kinston, W. (1983). A theoterical context of shame. Int J Psychoanal, 64, 213-226.

Laín Entralgo, P. (1975). Cansancio de la vida y desesperanza. En J. Rof Carballo, El cansancio de la vida (pp. 259275). Madrid, España: Karpos.

Laín Entralgo, P. (1978). Antropología de la esperanza. Madrid, España: Guadarrama.

Lansky, M. R. (2007). Unbearable shame, splitting and forgiveness in the resolution of vengefulness. Journal of the American Psychoanalitic Association, 55(2), 571-593.

Lester, D. (2006). Understanding suicide through studies of diaries: the case of Cesare Pavese. Arch Suicide Res, 10(3), 295-302. doi:10.1080/13811110600583750

Levi, P. (2005). Trilogía de Auschwitz. Si esto es un hombre. La tegua. Los hundidos y los salvados. Barcelona, España: El Aleph.

Martin, C. D. (2006). Ernest Hemingway: A Psychological Autopsy of a Suicide. Psychiatry: Interpersonal and Biological Processes, 69(4), 351-361.

Mishima, Y. (1985). Confesiones de una máscara. Barcelona, España: Seix Barral.

Mishima, Y. (2010). El sol y el acero. Madrid, España: Alianza.

Morrison, A. P. (1997). La cultura de la vergüenza. Anatomía de un sentimiento ambiguo. Barcelona, España: Paidós.

Morrison, A. P. (2008). Fenómenos narcisistas y vergüenza. Clínica e Investigación Relacional, 2(1), 9-25.

Ortega y Gasset, J. (1966). ¿Qué es filosofia? Madrid, España: Revista de Occidente.

Ortega y Gasset, J. (1974). Unas lecciones de metafisica. Madrid, España: Revista de Occidente.

Pavese, C. (1976). El oficio de vivir. Diario (1935-1950). Buenos Aires, Argentina: Siglo Veinte.

Rendueles, G. (2018). Suicidio(s). Madrid, España: Grupo 5. 
Rocamora A. (2017). Cuando nada tiene sentido. Reflexiones sobre el suicidio desde la Logoterapia. Bilbao, España: Desclée De Brouwer.

Rojas, E. (1978). Estudios sobre el suicidio. Barcelona, España: Salvat.

Sartre, J. P. (1996). El ser y la Nada. Ensayo de ontología y fenomenología. Buenos Aires, Argentina: Losada. Tangney, J. P. y Dearing, R. (2002). Shame and guilt. Nueva York, NY: Guilford Press.

Thomas, J. (Productor) y Bertolucci, B. (Director) (1990). El cielo protector [Película]. Londres, Reino Unido: Warner Bros.

Unamuno, M. (1982). Niebla. Barcelona, España: Orbis.

Ushijima, S. (1987). The narcissism and death of Yukio Mishima-from the object relational point of view. Japanese Journal of Psychiatry and Neurology, 41(4), 619-28.

van Heeringen, K. (2012). Stress-Diathesis Model of Suicidal Behavior. En Y. Dwivedi (Ed.), The Neurobiological Basis of Suicide. Boca Raton, FL: CRC Press/Taylor \& Francis.

Villegas, M. (2011). El error de Prometeo. Psico(pato)logía del desarrollo moral. Barcelona, España: Herder.

Villegas, M. (2013). Prometeo en el diván. Psicoterapia del desarrollo moral. Barcelona, España: Herder.

Villegas, M. (2015). El proceso de convertirse en persona autónoma. Barcelona, España: Herder.

Villegas, M. (2018). La teoría del desarrollo moral en el marco del análisis existencial. Revista de Psicoterapia, 29(109), 1-38. Recuperado de: http://tienda.revistadepsicoterapia.com/catalog/product/view/id/1480/s/ rp109-01/category/3/

Yalom, I. D. (1984). Psicoterapia Existencial. Barcelona, España: Herder.

Yalom, I. D. (2000). Psicoterapia existencial y terapia de grupo. Barcelona, España: Paidós.

Yalom, I. D. y Yalom, M. (1971). Ernest Hemingway: a psychiatry view. Archives of General Psychiatry, 24(4), 585-494.

Yalom. I. D. (2008). Mirar al sol. La superación del miedo a la muerte. Buenos Aires, Argentina: Emecé. 